\title{
AVALIAÇÃO DA DURAÇÃO DO DESEMPREGO NAS REGIÕES METROPOLITANAS DE SALVADOR E DE SÃO PAULO*
}

\author{
Wilson F. Menezes ${ }^{* *}$
}

\section{Cláudio S. Dedecca ${ }^{* * *}$}

RESUMO Este trabalho analisou a duração completa do desemprego nas regiões metropolitanas de Salvador e de São Paulo, no período compreendido entre 2000 e 2002. Para tanto, utilizou-se de uma amostra de 25.477 pessoas da RMS e de 28.285 da RMSP, cujas informações foram levantadas pela Pesquisa de Emprego e Desemprego. O procedimento metodológico busca estimar essa duração por meio de dados cross-section e do uso de coortes de desempregados em um período selecionado. O objetivo é verificar a probabilidade de passagem de uma coorte à outra, tal como sugerido por Sider (1985), Corak e Heisz (1995b) e Baker, Corak e Heisz (1996). As durações completas foram calculadas por três formas de medida: duração para trás, em estado estacionário e duração para a frente. A incidência de desempregados e as participações no estoque foram ainda estimadas, por sexo, cor, condição de chefe de família, de jovem e faixas de escolaridade. Foi também verificada a influência que a taxa de desemprego exerce sobre a duração do desemprego. Os resultados apontam uma duração média em estado estacionário de 9,4 meses para a RMS e de 8,8 meses para a RMSP, quando as durações incompletas foram estimadas em 22,3 e 19,5 meses, respectivamente.

Palavras-chave: desemprego; duração do desemprego; mercado regional de trabalho

Código JEL: C21, J61, J64

* Artigo recebido em 20 de setembro de 2004 e aprovado em 5 de dezembro de 2005. Os autores agradecem e acatam os procedentes comentários e observações dos pareceristas anônimos da Revista de Economia Contemporânea.

** Professor do Curso de Mestrado em Economia da Universidade Federal da Bahia (CME-UFBa) e doutor pela Universidade de Paris I, e-mail: awilson@ufba.br

*** Professor do Instituto de Economia da Universidade Estadual de Campinas (IE-Unicamp) e doutor pela Unicamp, e-mail: cdedecca@eco.unicamp.br 


\title{
ESTIMATION OF UNEMPLOYMENT DURATION IN THE METROPOLITAN AREA OF SALVADOR AND SÃO PAULO
}

\begin{abstract}
This article analyzed the unemployment duration of the metropolitan areas of Salvador (RMS) and São Paulo (RMSP), in the period between 2000 and 2002. For that, it has been used a sample of 25,477 people in RMS and 28,285 people in RMSP, whose information were collected by the Employment and Unemployment Research (PED). The methodologial procedure intends to estimate the unemployment duration by the cross-section data and by cohort groups of unemployed people in the determined time. The goal is to verify the probability of changing from one cohort to another one, as sugested by Sider (1985), Corak and Heisz (1995b) and Baker, Corak and Heisz (1996). The complete duration has been calculated by three ways: backward condition, steady state condition and forward condition. The incidence and the stock of unemployed people have been estimated by gender, race, chief of family, young, ranges of ages and ranges of years of study. It has also been analyzed how the unemployment rate effects on the unemployment duration. The results showed an average duration in steady state of 9.4 months in RMS and 8.8 months in RMSP, in contrast with the incomplete duration of 22.3 months in RMS and 19.5 months in RMSP.
\end{abstract}

Key words: unemployment; unemployment duration; regional work markets 


\section{INTRODUÇÃO}

Para avaliar as condições de funcionamento do mercado de trabalho, a taxa de desemprego é o mais citado indicador da conjuntura econômica. Essa taxa permite medir a proporção da mão-de-obra disponível não utilizada na atividade econômica. As variações dessa taxa são condicionadas por diversas forças, dentre as quais se destaca o tempo de duração do desemprego. A intuição econômica aponta que quanto maior o tempo de desemprego de um determinado indivíduo, menor sua chance de sair da condição em que se encontra.

A duração do desemprego apresenta diversas causalidades. Um importante condicionante dessa duração, sem dúvida, é sua própria extensão. Pode-se, então, argumentar que quanto maior o tempo de desemprego, mais se aumenta o risco de permanecer nessa condição; de maneira que se deve acrescentar a duração do desemprego às dificuldades do próprio desemprego (Bardoulat, Dejemeppe e Saks, 1998).

Outro importante item na relação de causas da duração do desemprego é a flutuação econômica, que acaba por condicionar situações diferenciadas entre os indivíduos desempregados. Nos períodos de desaceleração econômica, quando as perspectivas de emprego encontram-se reduzidas, nem todas as pessoas que querem trabalhar efetivamente procuram uma ocupação. Isso porque aquelas que já estão fora do mercado há mais tempo se desencorajam mais facilmente, tendo em vista uma perspectiva pessimista quanto à condição do mercado de trabalho.

A dificuldade de encontrar uma ocupação decorre ainda de uma inadequação da qualificação individual, que se deteriora à medida que o tempo de desemprego se estende, ou mesmo de uma subocupação a que o indivíduo se entrega tendo em vista sua sobrevivência imediata. Atividade essa que pode estar sendo exercida em tempo parcial ou sem grandes relações com sua qualificação, possibilidades e anseios, mas que, de alguma forma, dificulta ou mesmo impede a continuidade intermitente da busca de uma ocupação mais harmônica com seus atributos produtivos.

Todas essas razões aumentam certamente a duração do desemprego, o que torna essa duração um importante indicador do nível e da qualidade de funcionamento do mercado de trabalho. Não obstante, as medidas de duração do desemprego disponíveis são medidas incompletas, dado que elas 
se referem ao tempo que vai da declaração até a data em que a questão foi posta pelo entrevistador. Fica-se então sem saber até quando a pessoa em questão ficará ainda desempregada, já que a condição de desemprego pode ter continuidade por mais um dia, uma semana, um mês etc. Assim, mesmo que se considere que a probabilidade de deixar o desemprego diminui com o tempo, não se sabe quanto tempo efetivamente essa pessoa ficará nessa situação. ${ }^{1}$ Dessa forma, é interessante dispor de uma medida apropriada do tempo de desemprego. ${ }^{2}$

Este trabalho tem por objetivo estimar medidas completas do desemprego para as regiões metropolitanas de Salvador e de São Paulo, entre os anos 2000 e 2002. Para tanto, utilizou-se uma amostra de 25.477 pessoas da RMS e de 28.285 da RMSP, ${ }^{3}$ cujas informações foram levantadas pela Pesquisa de Emprego e Desemprego. ${ }^{4} \mathrm{O}$ texto encontra-se dividido em três seções, além desta introdução. Na seção 1 discute-se o modelo de duração completa, bem como se apresentam a definição das coortes e os procedimentos para se chegar à incidência e ao estoque de desempregados. Na seção 2 são apresentados os principais resultados das durações completas estimadas. A seção 3 apresenta uma análise da incidência sobre a duração completa do desemprego. Finalmente, algumas conclusões são relatadas na seção 4.

\section{NECESSIDADE DE UMA MEDIDA COMPLETA DA DURAÇÃO DO DESEMPREGO}

Segundo Corak e Heisz (1995a), uma medida consistente e completa da duração do desemprego se faz necessária por duas razões. Em primeiro lugar, a taxa de desemprego não tem condição de especificar a verdadeira condição de funcionamento do mercado de trabalho. Isso porque ela não informa se uma determinada taxa de desemprego se refere a um percentual de pessoas que em cada mês entra na condição de desemprego, mas sai rapidamente dessa condição, ou se esse percentual é o mesmo, mas as pessoas ficam um longo período desempregadas. Por exemplo, uma taxa de desemprego de $10 \%$ pode estar revelando que $10 \%$ da população economicamente ativa torna-se desempregada a cada mês, mas fica desempregada apenas algumas semanas; uma taxa de desemprego de $10 \%$ pode também estar revelando que essas pessoas estão ou estarão desempregadas por um ano ou mais. 
Trata-se de duas situações bem distintas, com repercussões diferenciadas sobre a vida dos desempregados.

Em segundo lugar, a medida incompleta da duração do desemprego apresenta uma situação enviesada da verdadeira condição de funcionamento do mercado de trabalho. Isso acontece por duas razões. Por um lado, em decorrência de a duração do desemprego (viés de duração) ser medida até o momento em que a questão é posta ao desempregado, essa medida subestima o verdadeiro tempo de desemprego das pessoas. Por outro lado, isso ocorre em face de um erro de amostragem implícito (viés de amostragem). Assim, quanto maior o tempo de desemprego de uma pessoa, maior também será a probabilidade de essa pessoa ser selecionada em uma amostra aleatória de desempregados, de maneira que as pessoas que passam por curtos períodos de desemprego acabam por ficar sub-representadas na amostra e a medida incompleta do tempo de desemprego, nessas condições, sobreestima a verdadeira duração do desemprego.

Assim, fica difícil avançar se a medida incompleta do tempo de desemprego subestima ou sobreestima a verdadeira temporalidade do desemprego. Em face desses problemas, Salant (1977) propõe que, na hipótese de a taxa de saída da condição de desemprego diminuir conforme a duração do desemprego se alongue, a medida média incompleta da duração do desemprego deve ser mais elevada que a medida média completa. Nessas circunstâncias, isso decorre do viés de amostragem que mais do que compensará o viés de duração do desemprego. No sentido oposto, se a taxa de saída da condição de desemprego for crescente ao longo da duração do desemprego, a duração incompleta será então menor que a duração média completa. Finalmente, se a taxa de saída do desemprego é constante ao longo da duração do desemprego, as duas medidas de duração, incompleta e completa, deverão se igualar.

Ademais, segundo Corak e Heisz (1995b), a medida de duração média incompleta do desemprego representa um indicador defasado em relação ao ciclo conjuntural da economia, medido pela taxa de desemprego. Dessa forma, no início de um processo recessivo, o grande fluxo de novos entrantes na condição de desemprego acaba por ter uma ponderação mais elevada. Isso porque a duração dos novos entrantes na condição de desemprego foi registrada apenas até a data em que a pesquisa foi realizada e essa data não 
registra ainda o verdadeiro teor da recessão que apenas se inicia, de maneira que a média incompleta fica subdimensionada, já que os novos entrantes no desemprego registram pequenas durações, mas certamente ficarão ainda por muito tempo como desempregados. Esse mecanismo se inverte para os momentos de retomada e expansão da economia, ou seja, o fluxo de novos entrantes diminui e o estoque de desempregados passa a contar com pessoas que já se encontram há mais tempo desempregadas. Isso faz com que a média incompleta do tempo de desemprego fique sobredimensionada.

Dessa forma, o principal motivo da diferença entre as durações completas e incompletas é encontrado no comportamento das taxas de incidência no desemprego. A duração incompleta subestima a verdadeira medida de duração do desemprego quando não se caracteriza uma dependência do desempregado ao tempo de desemprego, de maneira que a taxa de saída do desemprego não fica obstruída pelo próprio tempo de desemprego (Salant, 1977). Espera-se, portanto, que uma medida completa da duração do desemprego apresente uma relação direta com a taxa de desemprego, de maneira que a duração completa do desemprego alcance seu auge quando a taxa de desemprego também encontrar seu ponto mais elevado, diminua quando a taxa de desemprego apontar uma redução e aumente quando a taxa de desemprego se encontrar em crescimento. Assim sendo, a medida completa do desemprego permite uma melhor avaliação do estado conjuntural da economia, tendo em vista que ela se expande imediatamente com a recessão e se contrai também imediatamente com a expansão econômica.

Uma medida completa da duração do desemprego leva a crer que seria necessário o acompanhamento, ao longo do tempo, de uma amostra de desempregados, registrando-se as saídas dessa condição desde o primeiro mês de desemprego, até quando se esgote toda a amostra e não haja mais nenhum desempregado do grupo amostral. Seria, portanto, necessário um acompanhamento longitudinal dessas pessoas, para que ao fim de toda situação de desemprego se possa estabelecer o tempo médio do grupo selecionado. Claro que esse seria um tratamento eficiente, mas também de custo elevado, caso esse procedimento fosse levado a termo periodicamente.

No entanto, pesquisas por amostragem permitem de maneira eficiente e menos onerosa que se estabeleça uma medida completa da duração do de- 
semprego. Basta que se acompanhe um grupo "sintético" de desempregados ao longo de um determinado período. Esse grupo é chamado de "sintético" exatamente porque se trata de um grupo em que as pessoas vão sendo substituídas ao longo do período em análise. ${ }^{5}$

O procedimento metodológico, para que se possa ter uma avaliação da duração completa média do desemprego desse grupo, consiste em classificar os declarantes na condição de desemprego, dentro do período em referência, em coortes de tempo de desemprego. Em seguida, devem-se acompanhar as probabilidades de passar para a coorte posterior, dado que o desempregado já se encontrava na faixa de menor tempo (um mês, por exemplo) e assim sucessivamente até que se esgotem todos os desempregados ao longo de todas as coortes estabelecidas. Dessa forma, estabelece-se a probabilidade condicional de se permanecer como desempregado. Para aplicar esse procedimento, duas dificuldades devem ser enfrentadas. A primeira tem a ver com o procedimento de mensuração da probabilidade de se passar da coorte inicial de desemprego à coorte seguinte e dessa à imediatamente posterior e assim sucessivamente, enquanto a segunda diz respeito à definição das coortes.

\subsection{Um modelo de duração completa do desemprego}

A duração média completa do desemprego pode ser calculada a partir de dados cross-section. O cálculo dessa duração consiste em acompanhar uma coorte de desempregados ao longo de um período selecionado. A Pesquisa de Emprego e Desemprego faz, a cada mês, o levantamento dos desempregados e registra, no momento da aplicação de seu questionário, há quanto tempo esse desempregado se encontra nessa situação. Diferentes indivíduos são entrevistados a cada mês e diferentes temporalidades incompletas do desemprego são registradas. Esses registros são então classificados nas coortes anteriormente apresentadas, quando se pode definir que as pessoas que se declararam desempregadas, em um determinado mês, por mais de 30 dias e menos de 60 dias irão constituir a coorte daqueles que entraram no desemprego naquele mês e continuam desempregados no mês seguinte. Esse procedimento será aplicado até que todas as coortes sejam plenamente preenchidas e não restem mais desempregados do grupo sintético para serem classificados. 
A duração média completa de desemprego pode ser determinada pela razão entre o total de indivíduos desempregados de uma coorte, ponderados pela extensão completa do intervalo de tempo em que eles se encontram, e o total de indivíduos da coorte imediatamente anterior. O somatório das razões de probabilidade permite que se determine a duração média completa do desemprego. Vale ressaltar que a primeira coorte, aquela dos indivíduos entrantes na condição de desemprego, é considerada a incidência do desemprego, dado que as pessoas dessa coorte estão desempregadas há menos de 30 dias; logo, no mês anterior elas não se encontravam nessa situação.

A partir desse critério e seguindo os passos de Sider (1985), pode-se definir a duração média completa do desemprego (D) como se segue:

$$
D=\sum_{x=1}^{n} \frac{x(f[x-1]-f(x))}{f(0)}=\sum_{x=0}^{n} \frac{f(x)}{f(o)}
$$

onde $f(0)$ representa o fluxo (incidência) de entrada no desemprego - ou seja, trata-se de um subconjunto de indivíduos que não estavam desempregados no mês anterior -, enquanto $f(x)$ é definido como o subconjunto de pessoas que permanecem desempregadas após cada período $x, \operatorname{com} x$ variando entre 0 e $n$.

Desenvolvendo a equação (1) chega-se a:

$$
\begin{aligned}
& D_{t}=1 \frac{f(0)-f(1)}{f(0)}+2 \frac{f(1)-f(2)}{f(0)}+3 \frac{f(2)-f(3)}{f(0)}+(\ldots) \\
& D_{t}=1-\frac{f(1)}{f(0)}+2 \frac{f(1)}{f(0)}-2 \frac{f(2)}{f(0)}+3 \frac{f(2)}{f(0)}-3 \frac{f(3)}{f(0)}+(\ldots) \\
& D_{t}=1+\frac{f(1)}{f(0)}-2 \frac{f(1)}{f(0)} \frac{f(2)}{f(1)}+3 \frac{f(1)}{f(0)} \frac{f(2)}{f(1)}+3 \frac{f(1)}{f(0)} \frac{f(2)}{f(1)} \frac{f(3)}{f(2)}+(\ldots)(2)
\end{aligned}
$$

Essa medida de duração é também chamada de duração para trás ( $b a-$ ckward), duração corrente ou probabilidade condicional, já que a equação (2) pode ser assim reescrita:

$$
P_{x, t}=\frac{f(x, t)}{f(x-1, t-1)}
$$


Considerando que

$\frac{f(1)}{f(0)}=p_{1} ; \frac{f(2)}{f(1)}=p_{2}$ e $\frac{f(3)}{f(2)}=p_{3}$

pode-se então reescrever a equação (2) como se segue:

$$
\begin{aligned}
& D=\left(1-p_{1}\right)+2 p_{1}\left(1-p_{2}\right)+3 p_{1} p_{2}\left(1-p_{3}\right)+\ldots=1+p_{1}+p_{1} p_{2}+ \\
& p_{1} p_{2} p_{3}+(\ldots)
\end{aligned}
$$

A equação (4) pode então ser representada de forma geral assim:

$$
D_{t}=\sum_{x=1}^{n} g(x)\left[\prod_{j=0}^{x-1} p_{j}\right]\left(1-p_{x}\right)
$$

onde $p_{0}$ é igual à unidade e representa a probabilidade de pertencer à coorte inicial, enquanto $p_{j}\left(1-p_{x}\right)$ constitui a parte da coorte original que deixa o desemprego após $x$ períodos e $g(x)$ pondera os indivíduos pela duração completa apropriada. Na equação $(2), g(x)=x$, o que significa dizer que a ponderação se fez em função da longitude do intervalo completo; isso implica que as pessoas desse intervalo ficam desempregadas até o fim do tempo desse mesmo intervalo.

Como $g(x)=x$, a equação (5) pode ser apresentada da seguinte forma:

$$
D_{t}=\sum_{x=1}^{n} \prod_{i=1}^{x} p(i, t)
$$

onde $n$ representa o número de meses. A equação (6) permite então estimar a duração média completa do desemprego. Isso é feito para um conjunto de pessoas desempregadas, mas que entram no desemprego em diferentes momentos e apresentam durações diferenciadas de desemprego.

Duas outras medidas de duração média completa do desemprego podem ser calculadas: a do estado estacionário (steady state) e a esperada (forward).

\subsection{Duração completa do desemprego em estado estacionário (steady state)}

A duração do desemprego em condições de estado estacionário leva em consideração a hipótese de que as condições econômicas passadas continuarão as mesmas no período atual, significando dizer que a taxa de desem- 
prego permanece constante ao longo de todo o período em análise. Nessas condições, a equação (3) assume a seguinte forma:

$$
P E E_{x, t}=\frac{f(x, t)}{f(x-1, t)}
$$

\subsection{Duração completa esperada do desemprego ou para a frente (forward)}

A duração completa esperada do desemprego está baseada na condição de que os desempregados de uma coorte permanecerão desempregados por mais um período e passarão, por conseguinte, à coorte posterior. A hipótese subjacente a essa medida de duração do desemprego é que as condições atuais prevalecentes na economia serão as mesmas no futuro. A equação (3) é então representada como a seguir:

$$
P E E_{x, t}=\frac{f(x, t)}{f(x-1, t+1)}
$$

\section{A DEFINIÇÃO DAS COORTES DE DURAÇÃO DO DESEMPREGO}

Em relação à duração do desemprego, as pesquisas por amostras normalmente registram a data que a pessoa declarou como início da condição de desemprego. A partir dessa data, até o momento do levantamento da informação, pode-se calcular a duração do desemprego. Trata-se de uma duração enviesada e incompleta, já que não é possível, de uma forma direta, se calcular o que aconteceu com o desempregado no momento subseqüente à entrevista. Mesmo assim, é essa referência temporal de entrada na condição de desemprego que constituirá o ponto de partida para que se possa estimar uma duração completa do desemprego.

A duração efetiva do desemprego, em grande parte, depende das características produtivas (escolaridade, qualificação e experiência) e dos atributos pessoais (gênero, cor e idade) de cada desempregado, além de também depender das condições de funcionamento da economia. Sabe-se que as características produtivas e os atributos pessoais são distribuídos de maneira heterogênea entre as pessoas, de modo que é de se esperar que aquelas que possuem menos capacidades, aptidões e possibilidades e sofrem mais os processos discriminatórios acabam por estender mais a experiência do 
desemprego, quando essa os alcança, reduzindo por conseqüência suas probabilidades de sair dessa condição.

As circunstâncias objetivas e subjetivas enfrentadas pelos diferentes indivíduos imprimem trajetórias diferenciadas em relação à duração do desemprego. Para alguns indivíduos essa trajetória pode resultar em uma dependência da duração do desemprego, de maneira que uma duração do desemprego será tão maior quanto mais longo for o tempo de desemprego enfrentado, ou seja, o tempo da duração influencia na própria duração. Isso acontece em virtude de as características dos desempregados serem heterogêneas em relação às suas habilidades, atitudes em face do risco e expectativas quanto à extensão do emprego etc. (Salant, 1977).

Mas a intuição permite adiantar que, para um conjunto de desempregados em que as peculiaridades produtivas e pessoais se misturam, a participação relativa no desemprego vai diminuindo à medida que a duração do mesmo se alonga no tempo. Portanto, é de se esperar que a freqüência dos desempregados, por tempo de desemprego, ao longo de um período se concentre nos primeiros meses de desemprego e vá diminuindo conforme a duração do desemprego vá se alongando. Nessas condições, a distribuição qui-quadrado constituiria a melhor representação dessa freqüência, cujo pico provavelmente estaria localizado no primeiro mês de desemprego.

No entanto, o padrão da freqüência do desemprego não acontece como se espera, ou seja, o movimento decrescente em relação à duração do desemprego não se verifica. Em lugar do esperado, verificam-se picos de concentração de desempregados com freqüências acumuladas até o primeiro mês, entre o segundo e terceiro meses, entre o quarto e o sexto meses, entre o sexto mês e um ano e até mais de um ano. Esse comportamento foi mais ou menos o mesmo para as regiões metropolitanas de Salvador e de São Paulo.

Para corrigir os vieses de resposta, a definição das coortes seguiu os padrões estabelecidos em estudos dessa natureza (Corak e Heisz, 1995b), procurando calcular uma taxa de persistência do desemprego em intervalos seqüencialmente maiores. Essa decisão busca localizar as mais elevadas freqüências de desempregados, além de procurar compactar o número de casos que vai diminuindo à medida que o total de desempregados vai sendo alocado nas diferentes coortes, ou seja, à medida que o limite do tamanho da amostra vai sendo alcançado. 
Histogramas da freqüência relativa do tempo incompleto de desemprego

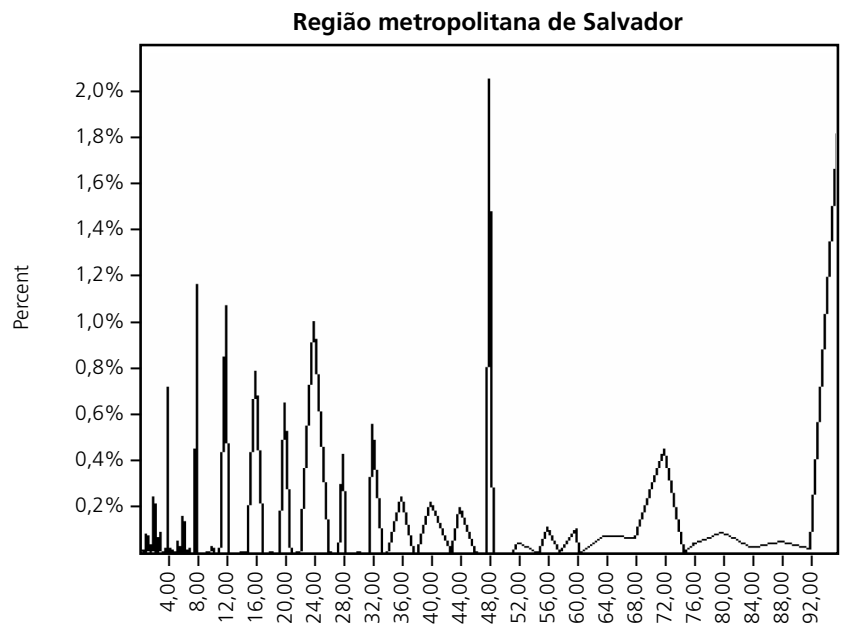

Temp desemp semana

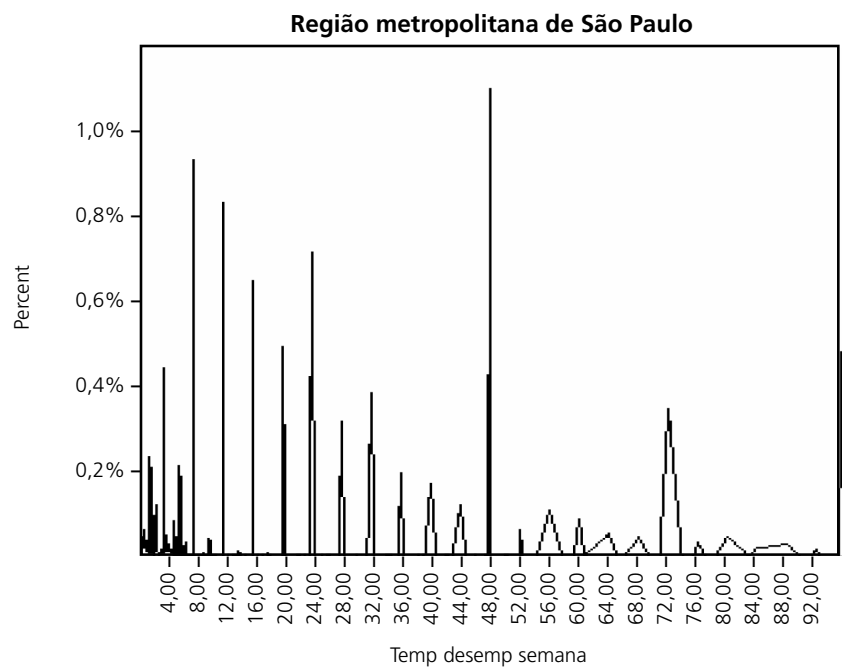


Dessa forma, levando-se em consideração os picos representados nos histogramas, procurou-se fixar os limites das coortes nos seguintes intervalos: até um mês; mais de um até três meses; mais de três até seis meses; mais de seis até 12 meses; e mais de 12 meses. As coortes construídas a partir desses intervalos têm por objetivo suavizar dois grandes problemas presentes nas respostas dos desempregados. O primeiro tem a ver com a preferência pelos números pares (digit preference), sobretudo quando o registro se faz em semanas (Baker, 1992), enquanto o segundo é relativo aos vieses de declaração do desempregado (Corak e Heisz, 1995b), que muito freqüentemente não sabe precisar de maneira exata há quanto tempo encontra-se desempregado e fornece respostas do tipo "por volta de um ano"; mesmo assim, a maioria prefere declarar o tempo de desemprego representado por números inteiros e não fracionados.

Assim, os intervalos das coortes vão se alongando - de um lado, porque quanto mais curtos os intervalos, mais evidente fica a preferência por números pares e, por outro, porque esse alongamento permite reduzir o viés das respostas imprecisas. As coortes assim definidas não estão isentas de custo. Dessa forma, se por um lado elas reduzem as distorções, por outro, elas tornam as estatísticas menos eficazes, na medida em que os desempregados localizados no interior de cada coorte são contabilizados pelo limite superior dessas mesmas coortes.

A definição das coortes corrigidas pelos intervalos seqüencialmente maiores tentou, portanto, aproximar-se daquilo que revelou a análise dos histogramas, quando foram localizados os picos de freqüência acumulada mais importantes. O primeiro desses picos foi localizado no primeiro mês de desemprego, ou seja, quando se verifica a entrada no desemprego, sendo, portanto, composto das pessoas com até um mês de desemprego.

Segue-se uma grande proporção de desempregados entre dois e três meses, refletindo uma dinâmica de uma coorte ainda entrante na condição de desemprego. Outro grande pico encontra-se localizado nos seis meses de desemprego, provavelmente refletindo realidades particulares, tais como redução das condições de sobrevivência, finalização do seguro desemprego, esgotamento do fundo de garantia, dentre outras possibilidades.

Por fim, percebe-se um pico de desempregados localizados nas imediações dos 12 meses de desemprego. Esse pico pode estar refletindo características similares às do pico dos seis meses, mas não se pode esquecer que os 
erros de resposta podem se apresentar mais fortemente quando a duração do desemprego se estende, já que a probabilidade de se estar procurando emprego fica bastante minimizada com o desenrolar do tempo. ${ }^{6}$

\subsection{Análise do estoque de desempregados}

Inicialmente, vamos estabelecer uma distinção entre a participação no fluxo e a participação no estoque de desempregados. Para tanto, necessário se faz separar distintos grupos de desempregados que se excluem mutuamente. A proporção de um grupo particular no fluxo é definida como a fração do número total de novos desempregados que compõem um determinado grupo. Assim, se um grupo é representado pelo subscrito “ $i$ ", tem-se então que $N_{i}(x, t)$ representa o número de pessoas desse grupo que estão desempregadas desde o mês $x$ no tempo $t$. Dessa forma, considerando-se o mês zero (primeiro mês de desemprego), a participação no fluxo do grupo $i$ no tempo té dada por:

$$
a_{i}(t)=\frac{N_{i}(0, t)}{N(0, t)}
$$

Por outro lado, a participação do grupo $i$ no total de efetivos de desempregados representa a proporção do número total de desempregados no tempo $t$ que forma esse grupo. Se $C_{i}(t)$ representa o número de desempregados que compõem o grupo $i$ no tempo $t$, tem-se então que a proporção do grupo no total de efetivos desempregados fica estabelecida por:

$$
e_{i}=\frac{C_{i}(t)}{C(t)}=\frac{N_{i}(0, t) D_{i}(t)}{N(0, t) D(t)}
$$

A segunda parte da equação (10) considera a hipótese do estado estacionário, quando o número de desempregados é igual ao produto da multiplicação da participação relativa dos novos desempregados do grupo $i$ pela participação relativa da duração média completa do grupo em referência, em um período já terminado, $D(t)$.

Combinando as equações (9) e (10), estabelece-se a relação entre a participação no estoque e a participação no fluxo da seguinte forma:

$$
e_{i}=a_{i} \frac{D_{i}(t)}{D(t)}
$$


A equação (11) mostra que a proporção do grupo $i$ no estoque é igual à sua proporção no fluxo ponderada pela duração relativa média completa do estado estacionário de um período de desemprego. Se o grupo $i$ enfrenta períodos de desemprego que têm, em média, a mesma duração do conjunto total de desempregados, segue-se que as participações no fluxo e no estoque serão iguais. Havendo diferença entre essas participações, essa diferença será tão mais expressiva na medida em que os grupos enfrentarem períodos de desemprego mais longos.

\section{AVALIAÇÃO DOS PRINCIPAIS RESULTADOS}

Os dados utilizados foram da Pesquisa de Emprego e Desemprego das regiões metropolitanas de Salvador e de São Paulo. Para essa pesquisa, existem duas situações de desemprego: desemprego aberto e desemprego oculto. O primeiro diz respeito às pessoas que procuraram trabalho de modo efetivo nos 30 dias anteriores ao dia da entrevista e não exerceram nenhum trabalho nos últimos sete dias. A segunda situação pode ser representada por duas circunstâncias: (a) por trabalho precário, quando os desempregados realizam de forma irregular, em caráter ocasional e eventual, algum trabalho remunerado, mas procuraram trabalho nos 30 dias anteriores ao dia da entrevista - caso não tenham procurado nesse período, o fizeram até 12 meses atrás; (b) por desalento, quando os desempregados não possuem trabalho nem o procuraram nos últimos 30 dias, por desestímulo do mercado de trabalho ou por circunstâncias fortuitas, mas procuraram efetivamente trabalho nos últimos 12 meses. O presente estudo incorporou as três formas de desemprego.

\subsection{Estimativa e análise das durações completas de desemprego}

Os resultados globais para as duas regiões metropolitanas encontram-se na tabela 1. Uma inspeção dessa tabela permite observar que a relação entre os desempregados com até um mês e o total de desempregados (taxa de incidência) aponta o percentual de desempregados entrantes na condição de desemprego. Essa taxa foi estimada em uma média de 3,2\% para a RMS e de $4,5 \%$ para a RMSP. Por outro lado, a duração incompleta foi estimada em 22,3 meses para a RMS e em 19,5 meses para a RMSP. 
Tabela 1: Durações médias completas do conjunto total dos desempregados*

\begin{tabular}{llccccc}
\hline Região & Estimativas & 2000 & 2001 & 2002 & Média & DP \\
\hline \multirow{4}{*}{ Salvadoropolitana } & Taxa de incidência & 3,2 & 3,1 & 3,4 & 3,2 & 0,02 \\
\cline { 2 - 7 } & Duração para trás & 5,9 & 10,1 & 9,3 & 8,4 & 2,3 \\
\cline { 2 - 7 } & Duração para a frente & 9,2 & 9,7 & 6 & 8,3 & 2 \\
\cline { 2 - 7 } & Estado estacionário & 9,3 & 9,7 & 9,1 & 9,4 & 0,3 \\
\cline { 2 - 7 } & Duração incompleta & 22,6 & 22,4 & 21,8 & 22,3 & 0,4 \\
\hline \multirow{3}{*}{ São Paulo } & Taxa de incidência & 4,4 & 4,7 & 4,3 & 4,5 & 0,02 \\
\cline { 2 - 7 } & Duração para trás & 5,6 & 8,8 & 9 & 7,8 & 1,9 \\
\cline { 2 - 6 } & Duração para a frente & 8,4 & 8,9 & 6,1 & 7,8 & 1,5 \\
\cline { 2 - 6 } & Estado estacionário & 8,6 & 8,9 & 8,9 & 8,8 & 0,2 \\
\cline { 2 - 6 } & Duração incompleta & 20 & 19,5 & 18,9 & 19,5 & 0,6 \\
\hline
\end{tabular}

*Taxas de incidência em percentual e durações em meses.

Quanto às durações completas, percebe-se uma situação mais grave para a RMS em relação à RMSP, isso porque as taxas completas de duração do desemprego foram mais elevadas na primeira região. Dessa forma, a esperança de retornar à ocupação é menor na RMS, muito embora os números de meses da RMSP sejam também bastante expressivos e próximos daqueles da RMS. Assim, as médias das durações completas para trás foram respectivamente de 8,4 e de 7,8 meses; das durações para a frente foram de 8,3 e 7,8 meses e das durações em condição de estado estacionário foram calculadas em 9,4 e 8,8 meses, também respectivamente. As variações em torno das médias das durações são mais importantes na RMS. Isso pode estar apontando que os grupos de desempregados internos aos tempos de duração são diferenciados e heterogêneos entre essas regiões.

As taxas de incidência e as durações do desemprego, segundo o gênero e a cor das pessoas, nas duas regiões, podem ser vistas na tabela 2. Uma análise dessa tabela permite dizer que a média da taxa de incidência para os homens foi calculada em 3,8\% para a RMS e em 5,3\% para a RMSP. A média da duração incompleta foi estimada em 18,8 meses para a RMS e em 14,6 meses para a RMS, enquanto as médias das durações completas para trás foram calculadas respectivamente em 8,2 e em 7,7 meses; as durações para a frente foram de 7,9 e 7,7 meses e as durações em condição de estado estacionário foram calculadas em 9 e 8,7 meses.

A taxa de incidência estimada para as mulheres foi em média de 2,7\% na RMS e 3,8\% na RMSP. As mulheres da RMS estão expostas a taxas completas 
de duração do desemprego mais elevadas para trás e em estado estacionário, enquanto as mulheres da RMSP enfrentam uma duração completa para a frente maior. As durações completas para trás foram respectivamente de 8,9 e de 8 meses; as durações para a frente foram de 9 e 8,1 meses e as durações em condição de estado estacionário foram calculadas em 10 e 9,1 meses. A duração incompleta foi mais elevada na RMS (24,3 meses) em relação à RMSP (22,9 meses).

Estimativas referentes aos desempregados segundo a cor podem também ser visualizadas na tabela 2. A taxa de incidência dos brancos da RMS (3,2\%) é mais elevada que a da RMSP (4,4\%). Isso demonstra que, relativamente à RMSP, na RMS a proporção de brancos entrantes no desemprego é maior em 1 ponto percentual. As durações completas dos brancos da RMS foram significativas apenas para a duração para a frente no ano de 2002, de maneira que a análise desse grupo de desempregados fica prejudicada para essa

Tabela 2: Taxas de incidência, durações médias completas e duração incompleta*

\begin{tabular}{|c|c|c|c|c|c|c|c|c|c|c|c|}
\hline \multirow[b]{2}{*}{ Atributo } & \multirow[b]{2}{*}{ Ano } & \multicolumn{5}{|c|}{ Região Metropolitana de Salvador } & \multicolumn{5}{|c|}{ Região Metropolitana de São Paulo } \\
\hline & & Incid. & $\begin{array}{l}\text { Para } \\
\text { trás }\end{array}$ & $\begin{array}{l}\text { Para a } \\
\text { frente }\end{array}$ & $\begin{array}{l}\text { Estado } \\
\text { estac. }\end{array}$ & Inc. & Incid. & $\begin{array}{l}\text { Para } \\
\text { trás }\end{array}$ & $\begin{array}{l}\text { Para a } \\
\text { frente }\end{array}$ & $\begin{array}{l}\text { Estado } \\
\text { estac. }\end{array}$ & Inc. \\
\hline \multirow{5}{*}{ Homem } & 2000 & 3,8 & 5,8 & 8,8 & 8,8 & 19,7 & 5,5 & 5,4 & 8 & 8,2 & 15,4 \\
\hline & 2001 & 3,7 & 9,7 & 9,1 & 9,3 & 18,3 & 5,5 & 8,8 & 8,8 & 8,9 & 14,1 \\
\hline & 2002 & 4 & 9,1 & 5,9 & 9 & 18,4 & 4,8 & 9,1 & 6,3 & 9 & 14,2 \\
\hline & Média & 3,8 & 8,2 & 7,9 & 9 & 18,8 & 5,3 & 7,7 & 7,7 & 8,7 & 14,6 \\
\hline & $\mathrm{DP}$ & 0,02 & 2,1 & 1,8 & 0,2 & 0,8 & 0,04 & 2,1 & 1,3 & 0,4 & 0,7 \\
\hline \multirow{5}{*}{ Mulher } & 2000 & 2,7 & 6,1 & 9,9 & 10 & 25,4 & 3,4 & 6 & 9,2 & 9,3 & 24,4 \\
\hline & 2001 & 2,5 & 10,7 & 10,7 & 10,3 & 26,4 & 4 & 9 & 9 & 9 & 24,7 \\
\hline & 2002 & 2,8 & 9,9 & 6,4 & 9,6 & 21,1 & 3,9 & 9 & 6 & 8,9 & 19,5 \\
\hline & Média & 2,7 & 8,9 & 9 & 10 & 24,3 & 3,8 & 8 & 8,1 & 9,1 & 22,9 \\
\hline & $\overline{D P}$ & 0,01 & 2,5 & 2,3 & 0,4 & 2,8 & 0,03 & 1,7 & 1,8 & 0,2 & 2,9 \\
\hline \multirow{5}{*}{ Branco } & 2000 & 3,2 & - & - & - & 20,8 & 4,5 & 5,4 & 8,4 & 8,5 & 20,5 \\
\hline & 2001 & 2,6 & - & - & - & 22,7 & 4,5 & 8,7 & 9,4 & 9,2 & 20,4 \\
\hline & 2002 & 3,7 & - & 6,1 & & 24,3 & 4,2 & 9,4 & 6,1 & 9,1 & 19,3 \\
\hline & Média & 3,2 & - & - & - & 22,6 & 4,4 & 7,8 & 8 & 8,9 & 20,1 \\
\hline & $\overline{D P}$ & 0,05 & - & - & - & 1,7 & 0,02 & 2,1 & 1,7 & 0,3 & 0,7 \\
\hline \multirow{5}{*}{ Negro } & 2000 & 3,2 & 5,8 & 9 & 9,2 & 22,8 & 4,4 & 6 & 8,6 & 9 & 19,2 \\
\hline & 2001 & 3,1 & 10,2 & 9,8 & 9,7 & 22,4 & 4,9 & 9,3 & 8,5 & 8,8 & 18,4 \\
\hline & 2002 & 3,4 & 9,4 & 6,1 & 9,2 & 21,6 & 4,4 & 8,8 & 6,3 & 8,9 & 18,5 \\
\hline & Média & 3,2 & 8,5 & 8,3 & 9,4 & 22,3 & 4,6 & 8 & 7,8 & 8,9 & 18,7 \\
\hline & $\overline{\mathrm{DP}}$ & 0,01 & 2,3 & 2 & 0,3 & 0,6 & 0,03 & 1,8 & 1,3 & 0,1 & 0,4 \\
\hline
\end{tabular}

* Taxas de incidência em percentual e durações em meses. 
região. Para o ano de 2002, as médias das durações incompletas das duas regiões foram estimadas em 24,3 meses para a RMS, contra 19,3 meses na RMSP. A média da duração incompleta, do período como um todo, foi calculada em 22,6 meses na RMS e em 20,1 na RMSP. Considerando apenas o ano de 2002, percebe-se que as durações completas para a frente são iguais nas duas regiões metropolitanas $(6,1)$.

A média da taxa de incidência estimada para os negros foi de $3,2 \%$ na RMS e 4,6\% na RMSP. As diferenças entre as durações completas e a duração incompleta aparecem em desfavor da RMS, já que as durações completas são mais elevadas nessa região. Com efeito, as medidas das durações completas para trás, para essas pessoas, respectivamente para a RMS e RMSP, foram estimadas em 8,5 e em 8 meses; das durações para a frente foram de 8,3 e 7,8 meses e das durações em condição de estado estacionário foram calculadas em 9,4 e 8,9 meses.

Uma avaliação da taxa de incidência e da duração do desemprego, para chefes de família, jovens, analfabetos e pessoas com escolaridade até o primeiro grau, pode ser vista na tabela 3. Uma inspeção dessa tabela permite afirmar que a média da taxa de incidência dos chefes de família é menos elevada na RMS $(3,8 \%)$ que na RMSP (5,6\%). Mas as durações completas e mesmo a duração incompleta são mais altas na RMS em relação à RMSP. O mesmo perfil de comportamento pode ser observado para os jovens, ou seja, as pessoas entre 16 e 25 anos enfrentam uma taxa de incidência menor na RMS, mas encontram-se expostas, relativamente à RMSP, a durações completas e incompletas mais elevadas na RMS.

Por fim, apresenta-se uma análise para os desempregados segundo duas faixas de escolaridade: pessoas com até dois anos de escolaridade (analfabetos funcionais) e pessoas entre três anos de escolaridade e o primeiro grau completo (tabela 3). Para os desempregados que têm até o primeiro grau completo, a média da taxa de incidência mostrou-se menos elevada na RMS, enquanto as durações completas estimadas foram mais elevadas nessa região relativamente à RMSP. Quanto à duração incompleta, pode-se afirmar que os desempregados com o primeiro grau completo da RMS enfrentam períodos mais longos de desemprego em relação ao mesmo agrupamento da RMSP. 
Tabela 3: Taxas de incidência, durações médias completas e duração incompleta*

\begin{tabular}{|c|c|c|c|c|c|c|c|c|c|c|c|}
\hline \multirow{2}{*}{ Atributo } & \multirow[b]{2}{*}{ Ano } & \multicolumn{5}{|c|}{ Região Metropolitana de Salvador } & \multicolumn{5}{|c|}{ Região Metropolitana de São Paulo } \\
\hline & & Incid. & $\begin{array}{l}\text { Para } \\
\text { trás }\end{array}$ & $\begin{array}{l}\text { Para a } \\
\text { frente }\end{array}$ & $\begin{array}{l}\text { Estado } \\
\text { estac. }\end{array}$ & Inc. & Incid. & $\begin{array}{l}\text { Para } \\
\text { trás }\end{array}$ & $\begin{array}{l}\text { Para a } \\
\text { frente }\end{array}$ & $\begin{array}{l}\text { Estado } \\
\text { estac. }\end{array}$ & Inc. \\
\hline \multirow{5}{*}{ Chefe } & 2000 & 4,1 & 5,4 & 8,8 & 8,4 & 19,7 & 5,6 & 5,4 & 7,6 & 8,3 & 15,4 \\
\hline & 2001 & 3,5 & 9,5 & 8,9 & 9 & 18,3 & 6,3 & 8 & 7,9 & 7,8 & 14,1 \\
\hline & 2002 & 3,8 & 8,9 & 5,6 & 8,8 & 18,4 & 5 & 8,3 & 5,9 & 8,6 & 14,2 \\
\hline & Média & 3,8 & 7,9 & 7,8 & 8,7 & 18,8 & 5,6 & 7,2 & 7,1 & 8,2 & 14,6 \\
\hline & DP & 0,3 & 2,2 & 1,9 & 0,3 & 0,8 & 0,7 & 1,6 & 1,1 & 0,4 & 0,7 \\
\hline \multirow{5}{*}{ Jovem } & 2000 & 4 & 5,9 & 9 & 9,2 & 12,7 & 5,2 & 5,7 & 8,6 & 8,7 & 12 \\
\hline & 2001 & 3,6 & 10,5 & 10,2 & 10,1 & 11,8 & 4,8 & 9,2 & 9,4 & 9,5 & 10,8 \\
\hline & 2002 & 3,9 & 9,8 & 6,3 & 9,4 & 12,5 & 5 & 9 & 6,1 & 8,9 & 10,8 \\
\hline & Média & 3,9 & 8,7 & 8,5 & 9,6 & 12,3 & 5 & 8 & 8 & 9 & 11,2 \\
\hline & DP & 0,2 & 2,5 & 2 & 0,5 & 0,5 & 0,2 & 2 & 1,7 & 0,4 & 0,7 \\
\hline \multirow{5}{*}{ Analfabeto } & 2000 & 4 & - & - & - & 24,6 & 6,7 & 4,9 & 7,6 & 7,5 & 22,6 \\
\hline & 2001 & 3,3 & - & - & - & 28,5 & 4,5 & - & - & - & 26,1 \\
\hline & 2002 & 4,3 & 9 & 5,5 & 8,5 & 26,5 & 5 & - & - & - & 25 \\
\hline & Média & 3,9 & - & - & - & 26,5 & 5,4 & - & - & - & 24,5 \\
\hline & DP & 0,5 & - & - & - & 1,9 & 1,2 & - & - & - & 1,8 \\
\hline \multirow{5}{*}{$\begin{array}{l}\text { Até o } \\
1^{\circ} \mathrm{grau}\end{array}$} & 2000 & 3,3 & 6 & 8,3 & 8,7 & 22,6 & 4,8 & 5,6 & 7,1 & 7,1 & 20,6 \\
\hline & 2001 & 3,4 & 9,7 & 8,7 & 8,7 & 22,3 & 4,6 & 8,9 & 8,4 & 8 & 20,6 \\
\hline & 2002 & 3,8 & 9,4 & 7,6 & 8 & 21,3 & 4 & 8,9 & 8,2 & 8,3 & 20,5 \\
\hline & Média & 3,5 & 8,4 & 8,2 & 8,5 & 22 & 4,5 & 7,8 & 7,9 & 7,8 & 20,6 \\
\hline & DP & 0,3 & 2 & 0,6 & 0,4 & 0,7 & 0,4 & 1,9 & 0,7 & 0,6 & 0,1 \\
\hline
\end{tabular}

* Taxas de incidência em percentual e duraçōes em meses.

\subsection{Estimativa e análise do estoque e do fluxo do desemprego}

Uma outra forma de visualizar o comportamento da duração do desemprego nas regiões metropolitanas de Salvador e de São Paulo é pela análise de dois aspectos bem diferenciados. O primeiro aspecto tem a ver com a participação relativa dos desempregados de cada grupo no estoque dos desempregados, enquanto o segundo analisa a heterogeneidade das durações do desemprego dos diferentes grupos nas duas regiões metropolitanas.

A participação relativa dos diferentes grupos de desempregados no estoque dos desempregados pode ser visualizada na tabela 4. Nas duas regiões, essa participação se mostra em desfavor das mulheres. Na RMS isso acontece porque a participação relativa das mulheres na ocupação, estimada em $46 \%$, é menor que a participação das mulheres no desemprego regional (51,7\%); da mesma forma, na RMSP a participação das mulheres na ocupação (calculada em 43\%) também é menor quando comparada com o peso das mulheres no desemprego (52,1\%). No que diz respeito à participação 
Tabela 4: Participação no estoque do desemprego

\begin{tabular}{|c|c|c|c|c|c|c|}
\hline Atributo & $\begin{array}{l}\text { Região } \\
\text { Metropolitana }\end{array}$ & 2000 & 2001 & 2002 & Média & $\mathrm{DP}$ \\
\hline \multirow{2}{*}{ Homem } & Salvador & 48,5 & 48,1 & 48,2 & 48,3 & 0,2 \\
\hline & São Paulo & 48,5 & 47,2 & 48 & 47,9 & 0,6 \\
\hline \multirow{2}{*}{ Mulher } & Salvador & 51,5 & 51,9 & 51,8 & 51,7 & 0,2 \\
\hline & São Paulo & 51,5 & 52,8 & 52 & 52,1 & 0,6 \\
\hline \multirow{2}{*}{ Branco } & Salvador & 9,5 & 8 & 9,8 & 9,1 & 0,9 \\
\hline & São Paulo & 62,2 & 56,5 & 55,3 & 58 & 3,7 \\
\hline \multirow{2}{*}{ Negro } & Salvador & 90,5 & 92 & 90,2 & 90,9 & 1 \\
\hline & São Paulo & 37,8 & 43,5 & 44,7 & 42 & 3,7 \\
\hline \multirow{2}{*}{ Chefe de família } & Salvador & 30,5 & 29,6 & 29,1 & 29,7 & 0,7 \\
\hline & São Paulo & 29,2 & 29,7 & 29,8 & 29,6 & 0,3 \\
\hline \multirow{2}{*}{ Jovem } & Salvador & 39,9 & 40,8 & 41 & 40,6 & 0,6 \\
\hline & São Paulo & 41,5 & 41,3 & 41,1 & 41,3 & 0,2 \\
\hline \multirow{2}{*}{ Analfabeto } & Salvador & 9,3 & 8,7 & 8 & 8,7 & 0,7 \\
\hline & São Paulo & 6,6 & 6,5 & 6,1 & 6,4 & 0,2 \\
\hline \multirow{2}{*}{ Até o $1^{\circ} \mathrm{grau}$} & Salvador & 50,8 & 47,6 & 46 & 48,1 & 2,5 \\
\hline & São Paulo & 50,5 & 49,4 & 46,6 & 48,8 & 2 \\
\hline
\end{tabular}

relativa dos desempregados na perspectiva da cor, verifica-se um desequilíbrio em detrimento dos negros da RMS, já que a participação relativa dessas pessoas no estoque de desempregados foi estimada em 90,9\%, quando elas representam $85 \%$ do total de ocupados. Na RMSP, os negros representam $32 \%$ dos ocupados, mas eles constituem $42 \%$ dos desempregados. O corolário desse quadro é que, nas duas regiões metropolitanas, homens e brancos desempregados têm pesos relativamente menores que suas respectivas participações relativas na ocupação.

A participação relativa dos chefes de família na ocupação foi estimada em $45,7 \%$ para a RMS e em $47,2 \%$ na RMSP, enquanto os desempregados chefes de família constituem $29,7 \%$ na primeira região e $29,6 \%$ na segunda, apontando que essas pessoas mostram-se mais dinâmicas no enfrentamento do desemprego. O inverso acontece com os jovens das duas regiões metropolitanas - isso porque suas respectivas participações relativas na ocupação foram calculadas em $24,9 \%$ na RMS e em $25,7 \%$ na RMSP, enquanto suas participações relativas no desemprego foram respectivamente de 40,6\% na RMS e de $41,3 \%$ na RMSP. Do ponto de vista da escolaridade, tem-se que os analfabetos funcionais representam 7,9\% dos ocupados na RMS e 6,4\% na RMSP, mas seus pesos relativos no desemprego são de 8,7\% e 6,4\%, respectivamente, para as duas regiões metropolitanas. Para os desempregados com 
escolaridade até o primeiro grau completo, observaram-se participações relativas na ocupação de $37,6 \%$ para a RMS e de $41,4 \%$ para a RMSP, mas suas participações relativas no desemprego mostraram-se mais elevadas nas duas regiões, ou seja, $48,1 \%$ para a RMS e $48,8 \%$ para a RMSP. Esses números podem estar caracterizando as dificuldades de reinserção dos diferentes agrupamentos quando enfrentam situações de desemprego.

O segundo aspecto, que se refere à heterogeneidade das durações do desemprego dos diferentes grupos, é analisado a partir das taxas de estoque e de fluxo de desempregados. A taxa de estoque é estimada por uma ponderação entre a taxa de fluxo de entrantes no desemprego e a participação relativa da duração do desemprego. Por taxa de fluxo entende-se a relação entre os entrantes no desemprego de um determinado grupo e os entrantes totais no desemprego; enquanto a participação relativa na duração é entendida como a relação entre a duração do desemprego dos diferentes grupos de desempregados e a duração do conjunto dos desempregados (conforme as equações 9, 10 e 11). Esse cálculo foi feito apenas para a condição de estado estacionário do desemprego - isso porque essa condição é que mais abranda os efeitos de uma distribuição incompleta para medir uma duração completa do desemprego, bem como em situações em que existe certa limitação de estimadores (Beker e Trivedi, 1985).

A taxa de estoque de desempregados e a taxa de fluxo devem ser iguais quando um determinado grupo de desempregados enfrenta uma duração média do desemprego igual à duração média do conjunto dos desempregados. Caso a taxa de estoque de um determinado grupo de desempregados seja mais elevada que a taxa de fluxo, isso quer dizer que esse grupo enfrenta uma duração completa do desemprego mais elevada que a duração média do conjunto dos desempregados. Inversamente, para uma taxa de estoque menor que uma taxa de fluxo, a duração média completa do grupo em referência é menor que a duração média do conjunto dos desempregados. Os resultados desses cálculos aparecem na tabela 5 .

Para os homens da RMS, a taxa de estoque de desempregados se mostrou, em média, menos elevada que a taxa de fluxo, permitindo dizer que esse grupo de desempregados enfrenta uma duração média completa do desemprego em condição de estado estacionário menor que a duração média do conjunto dos desempregados. O corolário da duração do desemprego dos 


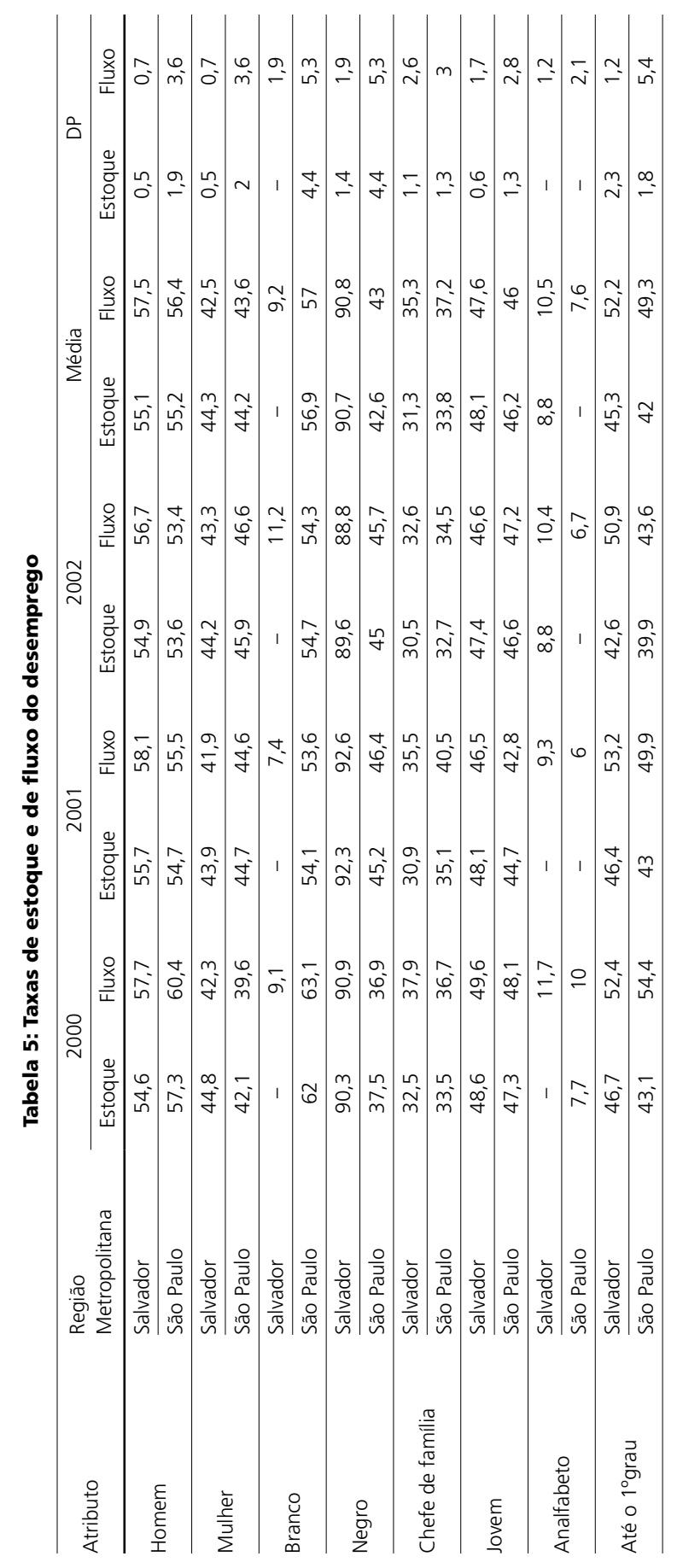


homens é que as mulheres apresentaram uma taxa média de estoque maior que a taxa média de fluxo, de sorte que as mulheres enfrentam durações do desemprego mais longas que a média dos homens. Na RMSP, os homens também enfrentam uma duração do desemprego menor que o conjunto dos desempregados dessa região, isso porque a taxa de estoque mostrou-se menos elevada que a taxa de fluxo. Por via de conseqüência, as mulheres da RMSP também enfrentam uma duração média do desemprego maior que a média dos desempregados, dado que a média da taxa de estoque para essas pessoas mostrou-se maior que a da taxa de fluxo.

Para os negros da RMS, tem-se uma duração média de desemprego análoga à média do conjunto dos desempregados, dado que essas pessoas apresentaram uma taxa de estoque praticamente igual à respectiva taxa de fluxo. No que diz respeito aos brancos da RMS, não se dispõe de informação estatisticamente significativa, mas, por comparação com os negros, conclui-se que os brancos também apresentam duração média completa bem próxima da média dos desempregados. Tanto os brancos quanto os negros da RMSP enfrentam durações médias praticamente iguais à média do desemprego do conjunto dos desempregados dessa região.

Para os chefes de família da RMS, tem-se uma duração média do desemprego menos elevada que a do conjunto dos desempregados, dado que essas pessoas apresentaram uma taxa de estoque menor que a respectiva taxa de fluxo. Situação análoga aparece para os chefes da RMSP, cuja taxa de estoque mostrou-se menos elevada que a taxa de fluxo. Quanto aos jovens, tem-se que na RMS eles enfrentam durações do desemprego mais longas que a média do conjunto dos desempregados dessa região, enquanto os jovens da RMSP se mostram mais dinâmicos no mercado de trabalho - isso porque a taxa de estoque dessas pessoas foi praticamente igual à média da taxa de fluxo, significando dizer que os jovens da RMSP enfrentam durações do desemprego na média de todos os desempregados dessa região.

Não se dispõem de informações completas para os analfabetos funcionais (com até dois anos de escolaridade) das duas regiões metropolitanas. Podese apenas afirmar que no ano de 2002 os analfabetos da RMS se mostraram relativamente dinâmicos no mercado de trabalho, ou seja, apresentaram uma taxa de estoque menor que a taxa de fluxo, condicionando uma duração do desemprego menor que a média dos desempregados dessa região. 
Para a RMSP, dispõem-se apenas dos resultados para o ano 2000, quando os analfabetos dessa região também se mostraram ágeis no mercado de trabalho, de maneira que essas pessoas acabaram por enfrentar uma duração do desemprego menor que aquela do total dos desempregados dessa região. Por outro lado, os desempregados da RMS com escolaridade entre três e oito anos (até o primeiro grau completo) apresentaram taxa de estoque inferior à taxa de fluxo, o que significa dizer que essas pessoas enfrentam durações menores do desemprego na média do total dos desempregados. Para a RMSP, essas pessoas também enfrentam durações do desemprego menores que as da média do conjunto dos desempregados - isso porque as taxas de estoque mostram-se menos elevadas que as taxas de fluxo.

\section{Algumas CONCLUSÕES}

Este trabalho analisou a heterogeneidade das durações do desemprego nas regiões metropolitanas de Salvador e de São Paulo. Para tanto, consideraram-se as incidências e as durações médias completas do desemprego. Os resultados encontrados permitem interpretações compatíveis com as de estudos que envolvem os métodos das medidas completas de duração. As duas regiões metropolitanas analisadas apresentaram durações completas menos elevadas que as respectivas durações incompletas. Isso quer dizer que as durações incompletas estão sobreestimando as verdadeiras durações do desemprego enfrentadas pelos diferentes grupos analisados.

Além disso, a Região Metropolitana de Salvador apresentou uma média de duração do desemprego superior à da Região Metropolitana de São Paulo. O diferencial em desfavor da RMS se manteve para todos os atributos pessoais analisados. Assim, em relação à RMSP, as durações médias completas da RMS mostraram-se mais elevadas para homens, mulheres e negros (não se pôde estabelecer uma comparação para os brancos, pois as informações sobre a RMS não apresentaram significância estatística). Também os chefes de família, os jovens, os analfabetos e aqueles indivíduos que possuem escolaridade até o primeiro grau apresentaram durações médias do desemprego superiores na RMS, relativamente à RMSP.

A participação relativa dos desempregados vistos por atributo pessoal no estoque de desempregados, quando comparada com a participação rela- 
tiva na ocupação, configurou uma situação em desfavor das mulheres e dos negros nas duas regiões metropolitanas. Essa mesma comparação se inverte para os chefes de família, ou seja, essas pessoas pesam mais na ocupação que no desemprego nas duas regiões analisadas. Os jovens, os indivíduos analfabetos e aqueles que têm até o primeiro grau pesam mais no desemprego que na ocupação.

As taxas de fluxo no desemprego, representando a entrada no desemprego por atributo pessoal sobre a entrada total no desemprego, mostraram-se mais elevadas para os homens da RMS, muito embora em ambas as regiões as taxas de fluxo tenham se mostrado mais elevadas para os homens que para as mulheres. Por outro lado, os negros da RMS apresentam um fluxo de entrada no desemprego proporcionalmente mais elevado que aquele da RMSP. Os chefes de família da RMS mostram uma taxa de fluxo menor, em relação à RMSP, enquanto as pessoas jovens, analfabetas e com até o primeiro grau da RMS têm taxas de entrada mais elevadas que seus análogos da RMSP.

Os resultados alcançados reforçam a necessidade de estudos dessa natureza, ao tempo em que se espera que as políticas sociais levem em consideração esses estudos, tendo em vista um maior entendimento do funcionamento dos mercados regionais de trabalho, bem como melhorem os focos e nichos de desemprego e, portanto, se aperfeiçoe a eficácia das ações.

\section{NOTAS}

1. Assim é que, em países economicamente mais avançados, o conceito de desemprego de longa duração é consagrado; da mesma forma que é interessante saber por que pessoas que passam pela experiência de um longo período de desemprego enfrentam maiores dificuldades para sair dessa situação.

2. Como bem salientaram Menezes-Filho e Picchetti (2002), "enquanto a literatura internacional já conta com uma série de trabalhos nessa direção, um dos primeiros trabalhos realizados para o Brasil é o de Bivar (1991)".

3. As amostras das regiões metropolitanas consideraram os desempregados com idade entre 18 e 60 anos, os quais foram agregados por mês de referência da pesquisa e ficaram distribuídos nos anos 2000, 2001 e 2002, respectivamente, da seguinte forma: RMS (8.761, 8.556 e 8.160) e RMSP (8.625, 9.540 e 10.120).

4. A PED é uma pesquisa mensal domiciliar por amostragem que segue a orientação metodológica da Fundação Seade do Estado de São Paulo e do Dieese. Essa pesquisa é atualmente realizada em cinco regiões metropolitanas (São Paulo, Belo Horizonte, Porto Alegre, Salvador e Recife), além do Distrito Federal (Brasília). 
5. Aqui é bom lembrar que a PED visita apenas uma vez seus entrevistados.

6. Esses picos foram suavizados levando-se em consideração as formas adotadas em estudos dessa natureza. Corak e Heisz (1995b) sugerem uma solução ad-hoc ao considerar os meses de 2,9 semanas, após observar que 30\% dos entrevistados têm tendência a declarar um período de desemprego inferior ao que efetivamente enfrentam. Essa subavaliação da duração do desemprego pôde ser notada ao verificar-se que, após meses consecutivos, os entrevistados informavam o mesmo tempo de desemprego. O procedimento aqui adotado consistiu em transferir 30\% dos desempregados localizados no último pico de cada coorte para a coorte imediatamente posterior.

\section{REFERÊNCIAS BIBLIOGRÁFICAS}

AVELINO, R. R. G. (2001) “Os determinantes da duração do desemprego em São Paulo”. Dissertação de mestrado. São Paulo: FEA-USP.

AZAR, P., RODÍGUEZ, S., SANGUINETTI, C. (2001) Análisis sobre la duración del desempleo: Uruguay (1986-1999). Asunción: Faculdad de Ciencias Económicas y de Administración de la Universidad de la República.

BAKER, M. (1992) "Digit preference in CPS unemployment data". Economic Letters, 39, p. $117-121$.

—, CORAK, M., HEISZ, A. (1996) “L'effectif et l'afflux de chômeurs”. Texto n. 97. Ottawa. , TRIVEDI, P. (1985) "Estimation of unemployment duration from grouped data: a comparative study". Journal of Labor Economics, v. 2, n. 21, p. 153-174.

BARDOULAT, I., DEJEMEPPE, M., SAKS, Y. (1998) Programme de valorisation des banques de données sócio-économique fédérales. Louvain: SSTC.

BIVAR, W. (1993) “Estimativas da duração média do desemprego no Brasil”. Pesquisa e Planejamento Econômico, v. 23, n. 2, p. 275-312.

CORAK, M, HEISZ, A. (1995a) Guide de l'utilisateur de la durée du chômage. Texto n. 84. Ottawa. (1995b )“Mesures de la durée moyenne du chômage”. Texto n. 83. Ottawa.

MENEZES FILHO, N., PICCHETTI, P. (2002) “Os determinantes da duração do desemprego no Brasil metropolitano: 1984-1998”. In: Mercado de trabalho no Brasil. São Paulo: LTr.

SALANT, S. (1977) "Search theory and duration data: a theory of sorts". Quarterly Journal of Economics, v. 91, p. 39-57.

SIDER, H. (1985) “Unemployment Duration and Incidence: 1968-82". The American Economic Review, v. 75, n. 3, Jun. 